

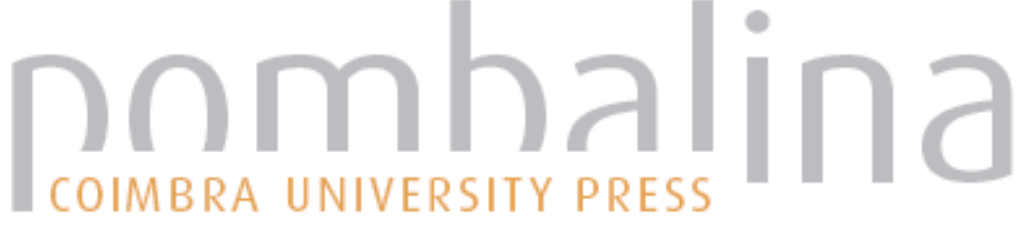

\section{Os vencedores dos jogos: a gloria na arte}
Autor(es): $\quad$ Pereira, Maria Helena da Rocha
Publicado por: Imprensa da Universidade de Coimbra
URL persistente:
URI:http://hdl.handle.net/10316.2/38364
DOI:
DOI:http://dx.doi.org/10.14195/978-989-26-0371-1_2

Accessed : $\quad$ 26-Apr-2023 12:48:51

A navegação consulta e descarregamento dos títulos inseridos nas Bibliotecas Digitais UC Digitalis, UC Pombalina e UC Impactum, pressupõem a aceitação plena e sem reservas dos Termos e Condições de Uso destas Bibliotecas Digitais, disponíveis em https://digitalis.uc.pt/pt-pt/termos.

Conforme exposto nos referidos Termos e Condições de Uso, o descarregamento de títulos de acesso restrito requer uma licença válida de autorização devendo o utilizador aceder ao(s) documento(s) a partir de um endereço de IP da instituição detentora da supramencionada licença.

Ao utilizador é apenas permitido o descarregamento para uso pessoal, pelo que o emprego do(s) título(s) descarregado(s) para outro fim, designadamente comercial, carece de autorização do respetivo autor ou editor da obra.

Na medida em que todas as obras da UC Digitalis se encontram protegidas pelo Código do Direito de Autor e Direitos Conexos e demais legislação aplicável, toda a cópia, parcial ou total, deste documento, nos casos em que é legalmente admitida, deverá conter ou fazer-se acompanhar por este aviso.




FRANCISCO DE OLIVEIRA

Coordenação

Ospírito Olímpico

no

novo milénio 


\title{
OS VENCEDORES DOS JOGOS: A GLORIA NA ARTE
}

\author{
Maria Hel ena da Rocha Pereira \\ Universidade de Coimbra
}

Embora os Grandes Jogos Pan-helénicos fossem quatro, como é sabido, até ao ponto de se ter consagrado um título especial, o de пврıобоvíkn9, para quem ficasse vencedor em todos eles, muitos outros se realizavam em várias localidades gregas(l). O destinatário da chamada X Nemeia de Pindaro, por exemplo, alcançara a vitória na cidade de Argos, nos jogos em honra de Hera, e contava na sua ascendência numerosas distinções semelhantes, ganhas em diversos certames (Nem. X. 43-46):

De Sícion regressaram cobertos de prata,

com taças para o vinho. De Pelena, com o dorso coberto de tecidos macios. Os prémios de bronze, aos milhares, nem podem enumerar-se...

De trechos como este é lícito concluir que os atletas recebiam, em muitos casos, prémios valiosos. Era o que se verificava também nos Jogos Panatenaicos, que, embora abertos a todos os helenos e, portanto, com o estatuto de Pan-helénicos, não eram contados entre os quatro maiores. Precisamente destes Jogos se conserva uma extensa inscrição do séc. IV a. C, com uma longa lista de prémios para as diversas modalidades de que constavam, a maioria dos quais era constituída por

\footnotetext{
O próprio Pindaro menciona ao todo mais de vinte jogos locais. Veja-se, a título exemplificativo, 01. XIII. 105- 113.
} 
dezenas de ânforas cheias de azeite das oliveiras sagradas, conquanto para algumas as recompensas variassem: coroas de ouro para a música, touros para as danças pírricas, corridas de archotes e regatas (diga-se de passagem que só nestes Jogos se realizavam competições aquáticas)(2). Pela mesma época, Aristoteles, na Constituição de Atenas LX, depois de descrever a organização do festival, apenas refere a atribuição de numerário e ouro aos vencedores da competição musical, de escudos aos da superioridade física(3), e de azeite para os concursos gímnicos e de corridas de cavalos.

Quanto aos quatro grandes Jogos, só há notícia, porém, da consagração do vencedor com uma coroa de oliveira brava em Olímpia, de loureiro em Delfos, de pinheiro no Istmo e de aipo em Nemeia, de acordo com as tradições míticas de cada um dos deuses ou heróis que se celebravam( $\left.{ }^{4}\right)$.

Esta parcimónia condiz com a informação, dada por Heródoto em passo célebre (VIII. 26), no qual refere a surpresa do rei da Pérsia, ao saber por uns transfugas da Arcádia que, mesmo em período de guerra, "os Helenos estavam a celebrar os Jogos Olímpicos e contemplavam os concursos gímnicos e hípicos". Perguntando ele qual era o prémio proposto, e sendo- Ihe respondido que era uma coroa de oliveira, e não dinheiro, Tritantaicmes, um dos homens do séquito real, exclama assustado: “Ai, Mardónio, que homens são esses contra quem nos levas a combater, se eles não lutam pela riqueza, mas só pela superioridade!"

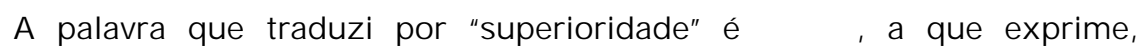
nesta época e neste contexto, um misto de coragem e de valor. É essa $\alpha \rho \varepsilon \tau n ́$ que se procura evidenciar nos Jogos, porque dela resulta a glória(5). Assim se lê no andante maestoso da abertura da VIII Olímpica de

(2) Trata-se do célebre bloco de mármore que se guarda no Museu Nacional de Atenas, /G 112 2311, reproduzido em Jenifer Neils et alii, Goddess and Polis. The Panathenaic Festival in Ancient Athens (Princeton 1992) 16. Para exemplos de outras localidades, vide M. I. Finley and H. W. Pleket, The Olympie Games (London 1976) 74.


mais do que um concurso de beleza masculina. Veja-se a este propósito H. W. Parke, Festivals of the Athenians (London 1977) 35- 37.

(4) Pausanias VIII. 48.2.

(5) Pindaro, 01. VII. 89. 
Pindaro, na magnífica evocação do cortejo nas margens do Alfeu (0/. VIII. 1-11):

Olímpia, mãe dos Jogos de áureas coroas, senhora da verdade, onde os adivinhos, observando o fogo dos sacrificos, experimentam Zeus, senhor do raio coruscante, sobre os seus desígnios para com os homens de espírito ansioso por atingir a supremacia ilustre, repouso dos seus trabalhos!

Obtêm o favor dos deuses as preces piedosas. Mas, ó santuário de Pisa, de belas árvores, junto do Alfeu, recebe esta procissão, que leva as coroas em triunfo! Grande, fulgente é a glória que sempre acompanha o teu prémio.

Porque, diz outro passo do mesmo poeta (01. I. 97- 99):

O vencedor goza, para o resto da vida, uma ventura doce como mel, graças aos prémios.

A mesma ode proclama, nos versos seguintes (01. I. 100- 104):
A mim me compete coroar
o ilustre patrono, em ritmo equestre e melodia eólia.
Creio que as pregas gloriosas dos meus hinos Jamais adornarão hóspede ao mesmo tempo mais apreciador da beleza e poderoso em força.

Uma das formas de perpetuar a glória alcançada nos Jogos é, pois, a sua celebração em epinícios - forma lírica destinada exclusivamente a esta finalidade, na qual concorrem duas artes, a poesia e a música. Compunham-nos, entre outros, dois dos maiores poetas gregos, como Simonides e Pindaro. Mas outras formas de arte a consagravam também. Quando o concorrente era um grande senhor da política, como os tiranos da Sicília (e o destinatário da ode que acabámos de citar, Hierão de Siracusa, era um deles), podia dar-se ao luxo de mandar cunhar uma moeda comemorativa. Vamos ver um exemplo que, ao mesmo tempo 
que demonstra a importância dos Jogos, comprova que a numismática grega não era uma arte menor [Fig. I], Trata-se de uma série de moedas de prata: a primeira é uma tetradracma de Siracusa, em que a Vitória ou Nike (figura à qual tornaremos adiante) coroa a quadriga de Gélon,



Figura I

tirano de Gela, que venceu a corrida de carros nos Jogos Olímpicos de 488; a seguinte é uma tetradracma de Régio, para celebrar uma vitória na corrida de carros de mulas do tirano daquela cidade da Itália do Sul, em Olímpia, em 480; a terceira, provém de Aspendos, na Ásia Menor, e diz respeito à luta; a quarta, ao lançamento do disco, por um atleta de Cós. Do primeiro motivo, ou seja, a Vitória a coroar a quadriga, existem dezenas de exemplares na colecção do Museu Gulbenkian, o melhor dos quais, como se sabe, foi escolhido para emblema da fundação.

Mas o nosso propósito é subir às artes maiores (mantendo a distinção tradicional, pouco do agrado dos actuais historiadores da especialidade, entre artes maiores e menores). Estamos a referir-nos, agora, à escultura. Como geralmente sucede, é Pausânias que, ao descrever o santuário de Olímpia, nos vai informar da amplitude do seu uso para esta finalidade (VI. I. I):

Segundo a ordem da minha exposição, depois da referência às oferendas votivas, faço menção dos cavalos dos concursos, dos atletas, e dos particulares igualmente. Não há estátuas erigidas a todos os que venceram em Olímpia, antes existem muitos que brilharam nas competições ou noutros feitos, e que não receberam estátuas. 
O nosso periegeta viveu no tempo de Adriano. Segundo a contagem dos helenos, os Jogos Olímpicos realizavam-se desde 776 a. C. Mesmo que as provas tivessem constado, inicialmente, apenas de uma corrida de 200 m, como é tradição, e que, de qualquer modo, não houvessem sido tantas como no tempo de Pindaro (em que somavam 14), e que o uso atlético da escultura de grandes dimensões não fosse prática corrente antes do séc. VI a. C., nessas celebrações quadrienais, no séc. II d. C. seria incontável o número de estátuas, se cada um tivesse a sua. Mas, que era elevado, prova- 0 , não só a descrição que se segue àquele texto, como os muitos plintos aparecidos no decurso das escavações do santuário, alguns dos quais com o nome de Policleto inscrito, o que significa que uma grande parte da obra de um dos maiores escultores gregos - de quem sabemos que representou sobretudo atletas - se encontrava naquele local sagrado.

Ora o facto de ser corrente mandar perpetuar no bronze a honra da vitória alcançada teve um papel determinante na evolução da escultura grega, porquanto deu lugar ao desenvolvimento da representação do nu masculino. Por outro lado, dada a continuidade da realização dos diversos festivais, que só vieram a ser extintos no final do séc. IV da nossa era, pelo edicto de Teodósio I, as obras conservadas, ou no original ou em cópias romanas, permitem-nos acompanhar as diferentes fases dessa arte.

E isso mesmo que vamos exemplificar, agrupando por temas obras executadas em diversas épocas.

Seja a primeira uma estatueta encontrada e conservada em Olímpia, que representa um cocheiro, ou, para empregar o latinismo consagrado para designar estas figuras, um auriga [Fig. 2]. De pequenas dimensões $(0 \mathrm{~cm}, 23)$, deixa entrever, pela posição das mãos, que segurava as rédeas dos cavalos. Os membros, bem destacados do torso que, por sua vez, tem já um apontamento de musculatura, levaram os especialistas a datá- lo dos meados do séc. VII a. C. Desta obra arcaica apenas podemos afirmar que era uma oferenda votiva ao santuário.

Mas, se passarmos para a primeira metade do séc. V a. C., ou seja, para aquela época que os historiadores da arte grega designam por estilo severo ou princípios do clássico ou ainda período de transição, e que uma frase muito expressiva de Gisela Richter caracterizou como "a 
passagem do arcaísmo à liberdade e experimentação"(6), depara-se- nos o mais famoso exemplo de auriga, o do Museu de Delfos [Fig. 3]. Deste, temos a certeza que conduziu a sua quadriga à vitória nos Jogos Píticos, quer fossem os de 478, quer os de 474 a. C. Do carro, apenas restam fragmentos; dos cavalos, patas e a cauda. Na mão direita, porém, o cocheiro segura ainda as rédeas. O seu rosto ovoide, emoldurado por



Figura 2



Figura 3

aneis de cabelo, tem marcas de arcaísmo, e a cara, levemente voltada para a direita, apresenta, para compensar esse desvio - como notou Boardman $\left({ }^{7}\right)$ - uma leve assimetria da face. Os olhos incrustrados e a fita de prata (emblema da vitória), o modelado do queixo e dos lábios contribuem para dar vida a esta figura revestida da túnica comprida que era então de regra para os aurigas, e que cai em pregas onduladas no tronco, a contrastar com as pregas verticais que, como caneluras de uma coluna, descem quase até aos pés. Uma inscrição revela o nome do vencedor - Polyzelos, senhor de Gela, um dos vários tiranos da Sicília que costumavam concorrer aos Grandes Jogos e disso se ufanavam. Mas, como os azares da política já então podiam chegar aos lugares sagrados,

(6) The Sculpture and Sculptors of the Greeks (New Haven, rev. ed. 1950) 199.

(7) Greek Sculpture. The Classical Period (London 1985) 52. 
a primeira linha do texto veio a ter de ser alterada, e a menção do controverso domínio sobre aquela cidade apagada. Uma reconstituição [Fig. 4] do conjunto deste monumento permite- nos visualizar melhor a sua imponência.



Figura 4

O motivo do auriga continuou o seu caminho na arte grega, ainda que não se tratasse, como naquele que acabámos de ver, de celebrar um concorrente aos Jogos. O exemplo presente [Fig. 5] é do séc. IV a. C., talvez de 360 a 350, e pertenceu a uma das sete maravilhas do mundo - o Mausoléu de Halicarnasso - onde é fama que trabalharam os maiores escultores da época, entre os quais Escopas. Se é dele ou não este auriga, não é certo. Mas tem os olhos



Figura 5 
encovados, irrequietos e expressivos, característicos do grande mestre. Também característico da nova época é o modo de sugerir o movimento rápido: o tronco inclinado para a frente, os cabelos quase na horizontal.

Vejamos agora o que nos mostra a pintura, não a grande pintura, que se perdeu na sua quase totalidade, mas o que dela podemos apreciar através das representações em cerâmica. Muitas delas encontram-se nas chamadas ânforas panatenaicas, que, cheias de azeite sagrado, eram, conforme vimos, dadas de prémio em muitas das competições. Na já citada X Nemeia, Pindaro faz- Ihes alusão (Nem. X. 33- 36):

.... Felizes augúrios, tal um prelúdio, já por duas vezes o acompanharam nas festas solenes dos Atenienses. E ao povo de Hera valente, já trouxe o fruto da oliveira, no recesso colorido dos vasos de barro, endurecidos ao fogo.

Ora estas ânforas tinham todas no anverso a figura da deusa Atena [Fig. 6], revestida com a égide e armada - como era habitual - com a lança, o capacete e o escudo. Ladeavam- na duas altas colunas dóricas,



Figura 6 
encimadas por galos (símbolo do espírito competitivo), e, ao longo de uma delas, podia ler-se uma inscrição que significava "Dos Jogos de Atenas". As linhas do vaso e o desenho da deusa foram evoluindo ao longo dos tempos. Mas a técnica das figuras negras (ou seja, de delinear a silhueta a verniz negro sobre o fundo vermelho do barro), que estava em uso quando, no séc. VI a. C, as competições atléticas se juntaram às cerimónias religiosas em honra da patrona da cidade, manteve-se inalterada, não obstante a gradual substituição dessa mesma técnica, a partir de c. 530 a. C., por outra mais expressiva, a das figuras vermelhas, que invertiam o esquema cromático, ou seja, cobriam de negro o fundo do vaso e deixavam reservado, na cor natural do barro, o espaço para o desenho.

E dessa origem ática esta ânfora [Fig. 7], encontrada numa cidade helénica do norte de África, Cirene. Pintada no final do séc. $V$ a. C., fazia parte dos prémios alcançados numa corrida de carros de cavalos. A quadriga avança a toda a velocidade, embora esteja a atingir o ponto mais perigoso - aquele em que era preciso tornear a curva. Por isso o auriga, com a sua longa túnica pintada de branco, puxa com maior cuidado as rédeas do cavalo do lado esquerdo.



Figura 7 
A corrida de carros de cavalos era a prova mais espectacular. Mas também havia corridas de cavalos [Fig. 8], que eram especialmente difíceis, se tivermos em conta que, como nos documenta o reverso desta outra ânfora panatenaica, anterior à antecedente em alguns decénios, os dois cavaleiros apenas dispõem de chicote e das rédeas



Figura 8

para governarem as suas montadas, porquanto os estribos só começaram a ser usados no séc. I da nossa era e a sela ainda mais tarde - só na Idade Média.

Especialmente interessante, para o ponto de vista que nos ocupa, é uma ânfora panatenaica decorada pelo "Pintor dos Baloiços" cerca de 530 a. C. Trata- se também de uma vitória na corrida de cavalos. No seu regresso, o premiado é escoltado pelo pai, que apregoa contente: "O cavalo de Dyskeiketos é vencedor".

Esta outra ânfora panatenaica [Fig. 9], pouco anterior a 500 a. C, representa uma das competições mais temidas, que ainda hoje fazem parte dos modernos Jogos Olímpicos: o pentatlo. Das cinco provas que - como o nome indica - o compunham, estão aqui representadas três: da esquerda para a direita, o lançamento do disco, o do dardo e o salto 
com pesos. Repare-se na variedade de posições dos diversos atletas e nos apontamentos da sua musculatura, obtidos pela técnica das incisões.



Figura 9

Do pentatlo fazia parte também a corrida [Fig. 10], que representam ambas estas ânforas panatenaicas, das quais a de cima é da mesma época das anteriores e a de baixo de 333/332 a. C. As técnicas usadas pelos


Figura 10 
atletas são distintas em cada uma delas; porquanto a primeira é uma prova de $200 \mathrm{~m}$, ao passo que a segunda é uma competição de longa distância, talvez de $4800 \mathrm{~m}$. O modo de correr é, por isso, diferente numa e noutra representação - como também diferente, devido à desigualdade de épocas, é a arte do desenho.

Mas as representações de jogos e de atletas não se limitam às ânforas panatenaicas, como é evidente. Assim, esta ânfora- de-colo ática de figuras negras, dos meados do séc. VI a. C, pintada, aliás, dois ou três decénios antes da introdução da respectiva prova nos Jogos Olímpicos [Fig. I I], mostra-nos um tipo de corrida diferente dos que vimos há pouco e certamente mais difícil: a que os atletas efectuavam revestidos de armas.



Figura II

O fundo de taça ática de figuras vermelhas singularizava um lançador de dardo. A coluna à direita assinala, provavelmente, o lugar de onde se efectuava o lançamento. Mas a atenção do jovem está toda voltada para o dardo que segura na mão direita, apoiando o dedo na tira de couro. O desenho dos olhos - com a pupila de perfil - e o das pernas e pés - um de lado, outro de frente - classificam a taça como pertencente 
ao estilo arcaico na maturidade (primeiro quartel do séc. $V$ a. C), ou seja, naquela fase decisiva em que a pintura passa de bidimensional a tridimensional.

Voltemos, porém, à escultura, onde veremos motivos semelhantes. Um exemplo é de novo uma figurinha votiva de bronze, com pouco mais de $10 \mathrm{~cm}$, encontrada em Olímpia. Que é votiva, confirma-o a inscrição que ostenta: "Pertenço a Zeus". O atleta prepara-se para iniciar a corrida. A inclinação pronunciada para frente e o desdobramento de planos nos membros superiores e inferiores, por um lado, e o tratamento arcaico do cabelo e dos olhos, por outro, datam-no do estilo severo.

Tivemos ocasião de avistar, na ânfora panatenaica com o pentatlo, um dos atletas no acto de lançar o disco. Os exemplos de estátuas de vulto, de que falaremos a seguir, referem-se à mesma actividade. Distam entre si perto de meio século, e a sua comparação serve, como poucas, para ilustrar a evolução no modo de representar o movimento. A primeira [Fig. 12] é uma estátua de bronze feita em Atenas nos começos do séc. $\mathrm{V}$ a. C. O atleta segura o disco com a mão esquerda, o que significa que está no primeiro momento da prova, aquele que precede a mudança de mão e o movimento rápido para trás. A perna



Figura 12 
direita um pouco avançada compensa, desde já, o equilíbrio da figura no seu conjunto.

A outra é talvez a mais reproduzida das estátuas de atletas, pelo que não a mostramos aqui. Desaparecido o original de bronze, da autoria do ateniense Míron, conservam-se sete cópias, das quais duas se encontram no Museo delle Terme, em Roma. Executada num só plano e com um só ângulo de visão, como se fosse um alto relevo, conforme escreveu Boardman(8), apresenta 0 braço direito no ponto mais recuado do lançamento, enquanto apoia o esquerdo no joelho, formando assim uma curva contínua que engloba os dois membros superiores, passando pela linha dos ombros. Encontrado no Esquilino, no séc. XVIII, pertence a um pequeno número de obras de arte grega identificadas através de textos literários (neste caso, de Luciano 34.18).

Míron ficou conhecido como escultor de atletas. Outro tanto sucedeu com outros grandes cultores dessa arte. Mais ainda, os cânones que vão começar a constituir-se logo a seguir escolhem esse motivo para se afirmar. Embora haja outras interpretações, será o caso do Doríforo [Fig. I 3] de Policleto, que, como já dissemos, fez principalmente estátuas



Figura 13

(8) Greek Sculpture. The Classical Period (London 1985) 80. 
de atletas. O autor tinha escrito um livro (e note-se a tendência dos artistas gregos para teorizar) e exemplificado os seus princípios na estátua deste nome. Um e outro se perderam, pelo que estamos reduzidos a conhecer apenas más cópias, das quais a melhor será a do Museu de Nápoles, a partir da qual se fizeram quatro tentativas de reconstituição do original. Por outro lado, o aparecimento, por voltas de 1976, de moldes de restos da perna esquerda, das duas mãos e do pescoço não é suficientemente elucidativa, pois desconhecemos os pontos usados como base. Do livro do cânon, conhecem-se três frases, das quais a mais discutida é a que observa que "o trabalho mais difícil é quando a argila chega à unha", mas a mais importante será a que revela a importância de conceitos estéticos como symmetria e harmonia.i ${ }^{9}$ )

Uma das grandes novidades desta obra consiste na aplicação da técnica chamada do contrapposto, que se conhece pela alternância entre membros tensos e relaxados combinada com a posição do torso (assim, a lança que está segura pela mão esquerda leva a que o ombro que lhe corresponde esteja levemente erguido, e o contrário sucede do lado oposto, no qual, por sua vez, o peso do corpo recai sobre a perna direita, de onde resulta que a anca fica mais elevada).

O esquema repete- se, com a variante de a figura [Fig. 14] ter os braços noutra posição, pois está a atar à cabeça as fitas da vitória, de onde a designação de Diadoumenos. Pelo que, neste caso, temos a certeza de que se trata de um vencedor nos Jogos.

Embora afirmasse que o Doríforo fora o seu modeloí10), Lisipo vai, no século seguinte, criar um novo cânone, exemplificado pelo Apoxyomenos [Fig. 15], ou seja, o atleta que está a raspar com a estrígil o excesso de óleo com que se ungiu. Também neste caso não sabemos, mau grado a descrição de Plínio-o-Antigo (34. 65), como definir com rigor o novo cânon, embora se tenha como certo que a cabeça era menor e "os corpos mais esbeltos e mais secos, de modo que a altura das estátuas parecia maior". Outra diferença visível nesta cópia é a cria-

(9) Sobre a questão, veja-se em especial Werner Gauer "Zu einem Zitat an das Kanon des Polyklet", Hermes 106 (1978) 43-48, e Andrew Stewart, "The Canon of Polykleitos", Journal of Hellenic Studies 98 ( 1978) 122- 131.

(10) Cf. Cícero, Brutus 296. 
ção de um espaço em frente da figura, com o lançamento dos dois braços para a frente, criando assim uma verdadeira tridimensionalidadeO '). E, portanto, como escreveu Boardman, "urna quebra manifesta com a composição essencialmente frontal"(12).



Figura 14



Figura 15

Embora não seja certa a atribuição a Lisipo, vale a pena considerar esta estátua de mármore de Agias [Fig. 16], um vencedor do pancrácio em Delfos. Que Lisipo executou uma deste mesmo vencedor para a família de Dáochos, em Farsália da Tessália, está confirmado por uma base aí encontrada, com a assinatura do artista. Quanto ao exemplar do Museu de Delfos, embora menos ousado do que os do mestre, apresenta as características do contrapposto, nomeadamente as ancas desniveladas. Mas, não menos do que a obra de arte, vale o significado da construção do monumento de Farsália, que prova que os dinastas da

(>') Cf. J. J. Pollitt, Art in the Hellenistic Age (Cambridge 1986) e sobretudo R. R. R. Smith, Hellenistic Sculpture (London 1991) 52.

(12) Greek Sculpture. The Late Classical Period (London 1995) 57. 
Tessália se gloriavam, à maneira helénica, de contar atletas vencedores entre os seus antepassados(13).

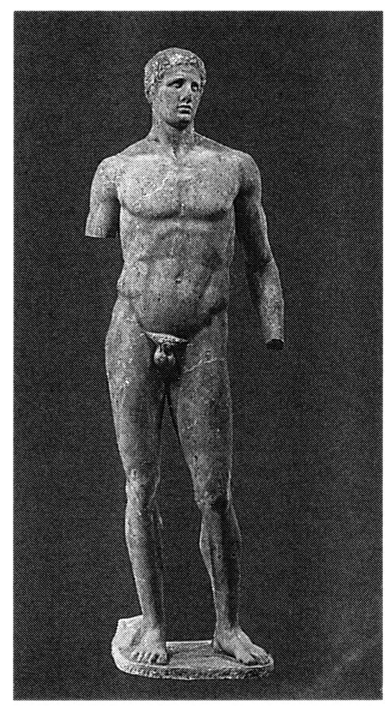

Figura 16

De Lisipo se sabe que começou a trabalhar em 370 a. C. e que ainda se encontrava em actividade na última década do séc. IV. Dele e dos seus discípulos se tem dito que estavam já a criar a escola helenística, de que a exploração do expressionismo emocional era uma característica inaugurada com a arte do retrato. Não será um desses retratos uma cabeça de pugilista, encontrada em Olímpia, pois há nos seus traços alguma idealização. No entanto, o modo de representar o nariz e as orelhas levam a identificar o género de desporto a que se dedicavaO4).

A obra prima neste domínio é o Jogador de Boxe do Museo delle Terme em Roma [Fig. 17]. "Brutalmente realista, com o seu cabelo curto, testa baixa, nariz quebrado, orelhas em "couve-flor", numerosas cicatrizes faciais em uma boca que sugere dentes partidos" - é como o

(14) Cf. J. Boardman, Creek Sculpture. The Late Classical Period, 70. 
descreve R. R. R. Smith, que aliás, também não o considera um retrato individuaK ${ }^{15}$ ). Todo o corpo é fortemente musculado e, mesmo num momento de repouso, em que parece estar atento a algumas instruções, se sente a enorme força nele contida.

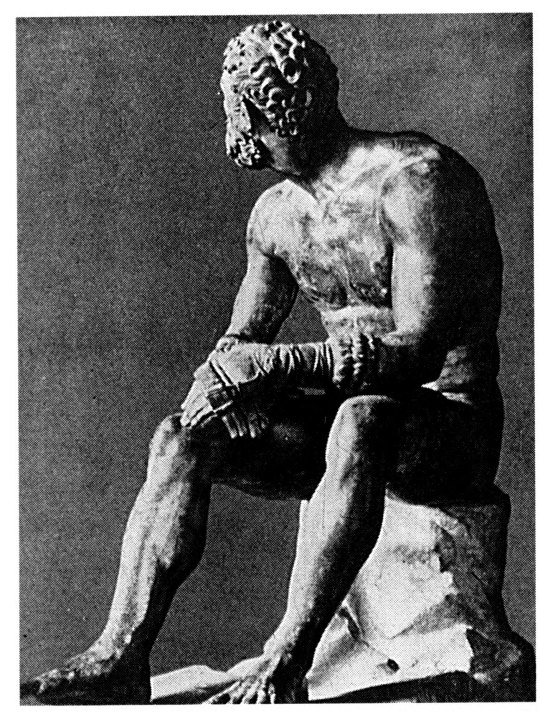

Figura 17

Neste breve percurso que fizemos por algumas das muitas obras de arte grega consagradas aos vencedores dos Jogos, vimos que, desde as figurinhas votivas em bronze às estátuas monumentais, sem esquecer as pinturas de vasos, a glória alcançada se perpetuava em todos os estilos. Uma divindade os coroava, conforme já vimos em moeda expressamente cunhada para o efeito - a Vitória ou Nike. Essa figura feminina, que aparece também em centenas de vasos gregos, a maior parte das vezes como auxiliar de deuses ou de guerreiros, é uma das personificações mais conhecidas da religião e da arte grega. Muito ligada, quer a Zeus, quer a Atena (e as famosas estátuas criselefantinas de um e outro deus, esculpidas por Fídias, aquela para o Templo de Olímpia, esta para 
o Pártenon, seguravam na mão direita essa figura alada(16)), o seu culto acaba por se fundir, em Atenas, com o da patrona da cidade, como o demonstra o Templo de Atena Nike, na subida para a AcrópoleC7). Mas, pelo que concerne à sua representação artística, torna-se um dos motivos escultóricos mais conhecidos^ $\left.{ }^{\wedge}\right)$.

Diziam os antigos que o primeiro artista a representar Nike com asas fora Archermos. Ora essa estátua de vulto apareceu, efectivamente, nas escavações de Delos, e pode hoje admirar-se no Museu Nacional de Atenas [Fig. 18]. Datável de c. 510 a. C., o artista representou- a com um



Figura 18

(16) Os dados provêm, mais uma vez, da descrição de Pausânias, V. ILI e I. 24.7, respectivamente. Atena Nike era a invocação do pequeno templo na encosta da Acrópole, e é com essa designação que aparece em incrições e no lexicógrafo Harpocrátion. Porém o


(I. 22.4; III. 15.7; V. 26.6). No segundo destes passos esclarece que os Atenienses explicavam a ausência das asas pelo empenho em que a deusa permanecesse sempre na sua cidade. Sobre a questão veja-se o sempre útil comentário de Blümner in Hitzig und Bliimner, Pausaniae Graeciae Descriptio (Berlin 1896) I. I, 245- 246.

(17) Sobre o caso especial de Nike, vide H. A. Shapiro, Personifications in Greek Art (Zürich 1993) 28- 29.

(18) O artigo 'Nike' no Lexicon Iconographicum Mythologiae Classicae, por Alexandra Goulaki-Voutira, menciona 730 exemplos em vasos, relevos, moedas e estátuas, dos quais 19 repeitam a atletas. 
joelho flectido - processo arcaico de sugerir o movimento rápido - e com o característico sorriso das imagens dessa época. Achados mais recentes dos meados deste século puseram a descoberto o braço da deusa e revelaram pormenores da variegada pintura do seu manto.

O segundo exemplo seleccionado [Fig. 19] é uma das obras mais famosas do santuário de Olímpia. Trata-se da Nike de Paiónios de cerca de 420 a. C., que comemorava a vitória alcançada, em 425, em



Figura 19

Esfactéria, pelos habitantes da Messénia e de Naupacto sobre os Atenienses. Trabalhada com a transparência nos drapejamentos característica da segunda metade do séc. $\mathrm{V}$ a. C., encimava uma coluna de cerca de $10 \mathrm{~m}$ de altura, e a sua dimensão aproximava-se, por sua vez, 42 dos dois metros. Estava representada no momento de se desprender dos ares, enquanto uma águia de asas abertas (símbolo de Zeus, a quem era dedicada), ficava a seus pés.

À época helenística vamos buscar o terceiro exemplo [Fig. 20], o mais conhecido de todos. A Nike de Samotrácia, com as suas enormes asas, feita em mármore de Paros, acaba de pousar na proa de um navio, o que significa que celebrava uma vitória naval. Muitas têm sido 
propostas para motivo desta honra, e a batalha de Áccio, embora pouco provável pela sua data tardia ( $3 \mid$ a. C), tem ainda defensores. Porém a conjugação dos dados históricos com a crescente influência do santuário de Samotrácia favorecem ou 306 ou 250 a. C. Tendo muito de clássico na transparência das vestes, que se colam ao corpo sob o ímpeto dos



Figura 20

ventos, a forte torsão do tronco, com as ancas numa direcção e o peito noutro, reflecte a estética helenística. Também desta figura se recuperaram ultimamente os braços, que foram entregues ao Museu do Louvre, mas não se encontram em condições de serem recolocados. Mantém-se, portanto, esta Nike do chamado barroco helenístico como mais um exemplo de que uma obra prima, mesmo mutilada, não perde a sua grandeza.

Comemorando a supremacia no combate e no desporto, a Nike era o coroamento natural do que Burckhardt chamou, com muita propriedade, o espírito agónico grego. E nesse sentido que entendemos que este motivo artístico servia, ele também, para simbolizar uma das mais altas manifestações desse desejo de superação. 